\title{
Erratum to: Mental health issues of refugee children: lessons from Croatia
}

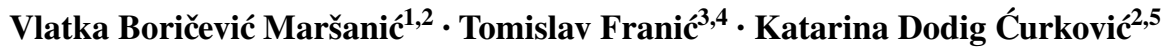

Published online: 6 February 2017

(C) Springer-Verlag Berlin Heidelberg 2017

\section{Erratum to: Eur Child Adolesc Psychiatry DOI 10.1007/s00787-016-0924-4}

Unfortunately, due to a technical error the article's title was not correctly included in the metadata of the first online publication.

The correct article title is as follows:

Mental health issues of refugee children: lessons from Croatia

The Original Article has been updated.

The online version of the original article can be found under doi:10.1007/s00787-016-0924-4.

Vlatka Boričević Maršanić

vlatka.boricevic@zg.t-com.hr

1 Psychiatric Hospital for Children and Adolescents, Kukuljevićeva 11, Zagreb, Croatia

2 Josip Juraj Strossmayer University of Osijek Medical School, Osijek, Croatia

3 Department of Psychiatry, University Hospital Center Split, Split, Croatia

4 School of Medicine, University of Split, Split, Croatia

5 Department of Child and Adolescent Psychiatry, University Hospital Center Osijek, Osijek, Croatia 